\title{
Prognostic Value of "Prepectoral Edema" in MR-mammography
}

\author{
CLEMENS G. KAISER ${ }^{1}$, MICHAEL HEROLD ${ }^{2}$, JULIA KRAMMER ${ }^{1}$, \\ PASCAL BALTZER ${ }^{3}$, MIECZYSLAW GAJDA ${ }^{4}$, OUMAR CAMARA ${ }^{5}$, \\ STEFAN SCHOENBERG ${ }^{1}$, WERNER A. KAISER ${ }^{3}$ and MATTHIAS DIETZEL ${ }^{6}$ \\ ${ }^{I}$ Institute of Clinical Radiology and Nuclear Medicine, University Medical Centre Mannheim, \\ Medical Faculty Mannheim-University of Heidelberg, Mannheim, Germany; \\ Institutes of ${ }^{2}$ Diagnostic and Interventional Radiology I, ${ }^{4}$ Pathology and ${ }^{5}$ Gynecology, \\ Friedrich-Schiller-University Hospital Jena, Jena, Germany; \\ ${ }^{3}$ Department of Biomedical Imaging and Image-guided Therapy, Medical University Vienna, Vienna, Austria; \\ ${ }^{6}$ Department of Radiology, University Hospital Erlangen, Erlangen, Germany
}

\begin{abstract}
Background/Aim: Previous studies have indicated a highly significant correlation between invasive tumors and accompanying prepectoral edema (PE) in MRmammography (MRM). The aim of the present study was to identify prognostic factors associated with $P E$ as a diagnostic sign. Materials and Methods: A total of 1,109 consecutive MRM exams were included in this study. Exclusion criteria were previous operation, biopsy, intervention, chemotherapy, hormone replacement therapy (HRT) or previous mastitis. One hundred and sixty-two patients with 180 lesions were evaluated and histologically correlated. Diagnostic evaluations were performed by four experienced radiologists in consensus. Results: One hundred and eighty lesions included 104 malignant lesions (93 invasive and 11 non-invasive) and 76 benign lesions. PE was detected significantly more frequently in presence of lymphangiosis carcinomatosa $((53.8 \% ; 14 / 26)$ vs. $(9.8 \%$; $4 / 41))(p<0,000)$. PE significantly correlates with positive axillary nodal status ((19.4\% (12/62) vs. $44.4 \%$ (12/27)) $(p=0.020)$, as well as pathologic enhancement of the pectoral muscle (5.4\% (5/93) vs. $22.7 \%(20 / 88))(p=0,015)$. $P E$ significantly correlates with higher tumor grading (G3) $(33.9 \%$ vs. $13.9 \%)(p<0.05)$. There was no significant difference in a positive vs. negative estrogen $(p=0.681)$ and
\end{abstract}

Correspondence to: Pascal Baltzer, MD, Department of Biomedical Imaging and Image-Guided Therapy, Division of Molecular and Gender Imaging, Medical University of Vienna, Waehringer-Guertel 18-20, Vienna, Austria, Tel.: +43 14040048180. E-mail: pascal. baltzer@meduniwien.ac.at

Key Words: MR-mammography, prepectoral edema, predictive value, diagnostic signs, morphology. progesterone $(p=0.751)$ and/or human epidermal growth factor receptor-2 (HER-2) $(p=0.726)$ receptor status accompanied by PE. Conclusion: The presence of PE may be a strong prognostic indicator for lymphatic spread and the cancerous infiltration of lymph nodes. It is also associated with the infiltration of the pectoral muscle, as well as high tumor grading. There is no correlation between prepectoral edema and positive tumor receptor status.

Magnetic resonance imaging (MRI) of the breast (MRmammography (MRM)) has evolved to be accepted as the most accurate imaging modality in the detection of breast cancer. The current guidelines of MRM are well-known and described by the American College of Radiology (ACR) (1). However, the increasing use of MRM has been accompanied by the ongoing discussion about appropriate technique and optimal accuracy, especially its specificity from the beginning.

For merely twenty years, specificity results have varied significantly (2), which raised the question as to the factors elevating the specificity of MRM.

Literature assumes that applying as many diagnostic signs (3), combined with high reader expertise in an optimal technical setting (4), will optimize MRM not only in its sensitivity but also in its specificity in detecting lesions. This is why more and more diagnostic signs are scientifically evaluated regarding their diagnostic accuracy in predicting benign and malignant lesions (5-8).

Additionally, there have been reports of single diagnostic signs, not only predicting a lesion in terms of malignancy (i.e. diagnostic information) but also containing prognostic information $(9,10)$, allowing prognosis in terms of tumor staging (11).

We have previously reported (12) that prepectoral edema (PE), as a morphological sign in the T2-weighted images in 
MRM among other tumor accompanying edema in the female breast, may implicate important diagnostic information about the local findings as PE significantly correlates with the presence of malignant, i.e. invasive tumors, independent from their entity (Figure 1). We were able to show that PE was detected in $2.6 \%$ of benign lesions $(2 / 76)$, none of the ductal carcinoma in situ (DCIS) cases (0/11) and $25.8 \%$ of malignant lesions $(24 / 93) \quad(p<0.000)$. PE was found significantly more frequently associated with malignant tumors above $2 \mathrm{~cm}$ in diameter $((47.1 \% ; 16 / 34)$ vs. (13.8\%; $8 / 58))(p<0.001)$. On the contrary, PE was not statistically associated to a specific malignant tumor-type (i.e. ductal invasive $v s$. lobular cancer), a possible presence or absence of additional DCIS foci or the number of foci.

Within this second part, we aimed to address the following question: "Apart from local diagnostic tumor findings, is there a potential prognostic value to $\mathrm{PE}$ in terms of a possible prognosis of lymphatic spread, i.e. the presence of lymphangiosis carcinomatosa, infiltration of axillary lymph nodes, infiltration of the pectoral muscle tumor grading or receptor status, hypothetically allowing for an extraction of information leading to potential changes in patient therapy?"

\section{Materials and Methods}

Study design. The patient collective is identical to the patient collective described in our previous study (12). A total of 1,109 MRM examinations were performed between January 2005 and October 2006 in our University Hospital.

Histopathology, performed in the Department of Gynecology of our University Hospital, served as reference standard in this retrospective evaluation.

Patients after previous operations, biopsy within the last 3 months, status after interventional therapy, hormone replacement therapy (HRT) within the last 6 weeks, status after previous chemotherapy, radiation therapy, mastitis, inflammatory cancer or tumors of nonmammary origin were excluded from this study. Patients with inflammatory cancers were excluded as they typically show extraordinary amounts of mammary edema in the entire breast.

Of 1,109 MRM examinations, 305 patients with 233 malignant and 131 benign breast lesions were identified. One hundred and forty-three patients were excluded due to criteria mentioned above.

One hundred and sixty-two patients with a total of 180 histologically-correlated lesions were included in the study. One hundred and twenty-four patients with 136 lesions underwent surgery. Thirty-eight patients with 44 lesions received a core biopsy. The mean patient age was $55.7+12.0$ years.

Statistical evaluation. The statistical evaluation was conducted using the Chi-square test and the exact Fisher's test within Microsoft Excel and SPSS (Version 15.0 for Windows; IBM, New York, USA).

Image acquisition and interpretation. Examinations were retrospectively evaluated by 4 experienced radiologists ( $>500$ MRM examination each) in consensus. Images were interpreted on a Siemens workstation (Syngo; Siemens AG, Erlangen, Germany). PE was defined as T2w-hyperintense fluid spatters and liquid layers prepectorally, accompanying a lesion.
MR-scanner. All MRM exams were performed with a 1.5 Tesla-MR Scanner (Siemens Symphony and Sonata; Siemens AG, Erlangen, Germany) using a standard protocol.

IRB approval statement. The study was IRB approved by the ethical review board. The need for informed consent was waived by the ethical review board. All imaging material was obtained from clinical routine.

\section{Results}

In total, 104 malignant (58\%) and 76 benign lesions (42\%) were identified and histologically correlated in 162 patients (Tables I and II). Malignant lesions could be correlated to 93 invasive and 11 non-invasive carcinomas (ductal cancer in situ (DCIS)/lobular carcinoma in situ (LCIS)) (12).

There were 76 findings of benign lesions (42\%) (12). PE could be histologically correlated to $2 / 76$ cases $(2.6 \%)$; one fibroadenoma and one case of focal inflammation. On the contrary, PE could be histologically correlated to $26 \%$ (24/93) of invasive cancers $(p<0.000)(12)$. This resulted in the following diagnostic parameters for PE as an indicator for malignancy: sensitivity of $19.3 \%$, specificity of $97.3 \%$, positive predictive value (PPV) of $92.3 \%$; negative predictive value (NPV) of $48 \%$; accuracy of $57.7 \%$ (12).

$\mathrm{PE}$ could be significantly correlated to the presence of an accompanying lymphangiosis carcinomatosa $(p<0.000)$. In case of a histologically proven lymphangiosis, PE was seen as an accompanying phenomenon in $53.8 \%(14 / 26)$, whereas lymphangiosis without PE could be detected in $9.8 \%(4 / 41)$ of cases (Table III).

The nodal status could be histologically determined in 95.7\% (89/93) of invasive cancers. A positive lymph node status could be correlated with higher prevalence of PE: Operated carcinoma with negative axillary nodal status showed a PE in $19.4 \%$ (12/62) of cases (Figure 2); carcinomas with positive nodal status showed accompanying PE in $44.4 \%$ $(12 / 27)$ of cases, resulting in a significant difference $(p=0.020)$ (Table I).

Of 93 invasive cancers, 5.4\% (5/93) showed a pathologic enhancement of the pectoral muscle. Eighty percent (4/5) of the cases involving an infiltration of the pectoral muscle coincided with the presence of PE (Table II), while PEs were only detected in $22.7 \%(20 / 88)$ of cases without pathologic muscle enhancement $(p=0.015)$.

Tumor grading could be determined for $98.9 \%$ (92/93) of invasive cancers in this study. An increasing prevalence of PE with decreasing degree of differentiation could be shown. Five out of $36(13.9 \%)$ cases of G2 cancers and $33.9 \%$ (19/56) of G3 cancers were accompanied by PE, resulting in a significant difference $(p<0.05)$. There were no G1 cancer cases in this study (Table IV).

The receptor status (estrogen, progesterone and HER-2) could be determined in $93.5 \%$ (87/93) of invasive cancers. 
Table I. Prepectoral edema (PE) and the infiltration of lymph nodes $(L N)(p=0.020)$.

\begin{tabular}{lccc}
\hline & No PE & PE & Total \\
\hline Negative axillary LN & $80.6 \%(50 / 62)$ & $19.4 \%(12 / 62)$ & 62 \\
Positive axillary LN & $55.6 \%(15 / 27)$ & $44.4 \%(12 / 27)$ & 27 \\
\hline Total & $73.0 \%(65)$ & $27.0 \%(24)$ & 89 \\
\hline
\end{tabular}

Table II. Correlation between prepectoral edema (PE) and infiltration of the pectoral muscle $(p=0.015)$.

\begin{tabular}{lccc}
\hline & No PE & PE & Total \\
\hline No pectoral infiltration & $77.3 \%(68 / 88)$ & $22.7 \%(20 / 88)$ & 88 \\
Pectoral Infiltration & $20.0 \%(1 / 5)$ & $80.0 \%(4 / 5)$ & 5 \\
\hline Total & $74.2 \%(69)$ & $25.8 \%(24)$ & 93 \\
\hline
\end{tabular}

Table III. Prepectoral edema (PE) in correlation to present lymphangiosis carcinomatosa $(p<0.001)$.

\begin{tabular}{lccc}
\hline & No PE & PE & Total \\
\hline Not present & $90.2 \%(37 / 41)$ & $9.8 \%(4 / 41)$ & 41 \\
Present & $46.2 \%(12 / 26)$ & $53.8 \%(14 / 26)$ & 26 \\
\hline Total & $73.1 \%(49)$ & $26.9 \%(18)$ & 67 \\
\hline
\end{tabular}

Table IV. Correlation between prepectoral edema (PE) and tumor grading $(p<0.05)$.

\begin{tabular}{lccc}
\hline & No PE & PE & Total \\
\hline G2 - moderate differentiation & $86.1 \%(31 / 36)$ & $13.9 \%(5 / 36)$ & 36 \\
G3 - worse differentiation & $66.1 \%(37 / 56)$ & $33.9 \%(19 / 56)$ & 56 \\
\hline Total & $73.9 \%(68)$ & $26.1 \%(24)$ & 92 \\
\hline
\end{tabular}

In patients with estrogen receptor-negative cancer, PE could be seen in $33 \%$ of cases (3/9). In patients with estrogen receptor-positive cancer, PE could be detected in $23.1 \%$ of cases (18/78). A significant difference could not be determined $(p=0.681)$ (Table V).

In patients with progesterone receptor-negative cancer, $\mathrm{PE}$ could be seen in $26.7 \%$ of cases $(4 / 15)$. In patients with progesterone receptor-positive cancer, PE could be detected in $23.6 \%$ of cases (17/72). A significant difference could not be determined ( $p=0.751)$ (Table VI).

In patients with HER-2 receptor-negative cancer, $\mathrm{PE}$ could be seen in $15.4 \%(2 / 13)$ of cases. In patients with HER-2
Table V. Estrogen receptor (ER) status in correlation with prepectoral edema $(P E)(p=0.681)$.

\begin{tabular}{lccc}
\hline & No PE & PE & Total \\
\hline ER receptor-negative & $66.7 \%(6 / 9)$ & $33.3 \%(3 / 9)$ & 9 \\
ER receptor-positive & $76.9 \%(60 / 78)$ & $23.1 \%(18 / 78)$ & 78 \\
\hline Total & $75.9 \%(66)$ & $24.1 \%(21)$ & 87 \\
\hline
\end{tabular}

Table VI. Progesterone receptor (PR) status in correlation with prepectoral edema $(P E)(p=0.751)$.

\begin{tabular}{lccc}
\hline & No PE & PE & Total \\
\hline PR receptor-negative & $73.3 \%(11 / 15)$ & $26.7 \%(4 / 15)$ & 15 \\
PR receptor-positive & $76.4 \%(55 / 72)$ & $23.6 \%(17 / 72)$ & 72 \\
\hline Total & $75.9 \%(66)$ & $24.1 \%(21)$ & 87 \\
\hline
\end{tabular}

Table VII. Human epidermal growth factor receptor-2 (HER-2) status in correlation with prepectoral edema (PE) $(p=0.726)$.

\begin{tabular}{lccc}
\hline & No PE & PE & Total \\
\hline HER-2 receptor-negative & $84.6 \%(11 / 13)$ & $15.4 \%(2 / 13)$ & 13 \\
HER-2 receptor-positive & $74.3 \%(55 / 74)$ & $25.7 \%(19 / 74)$ & 74 \\
\hline Total & $75.9 \%(66)$ & $24.1 \%(21)$ & 87 \\
\hline
\end{tabular}

receptor-positive cancer, PE could be detected in $25.7 \%$ (19/74) of cases. A significant difference could not be determined $(p=0.726)$ (Table VII).

\section{Discussion}

In the last years we have witnessed an increasing interest in the use of MRM as a prognostic tool using both functional and morphological imaging data $(9,10,13,14)$.

We assume that the dorsal localization of PE may be explained pathophysiologically through the anatomy of lymphatic drainage pathways, indicating a possible correlation between PE and lymphatic spread. Blocked lymphatic trails and nodes could be responsible for some sort of lymphatic obstruction within the breast and explain the formation of PE.

Perifocal edema can often be detected around tumors (1517), which is mainly thought to be caused by the immunohistopathologic response of the body against tumors through emitting cytotoxic T-cells, natural killer cells and macrophages. Tumor-associated macrophages (TAM) are 

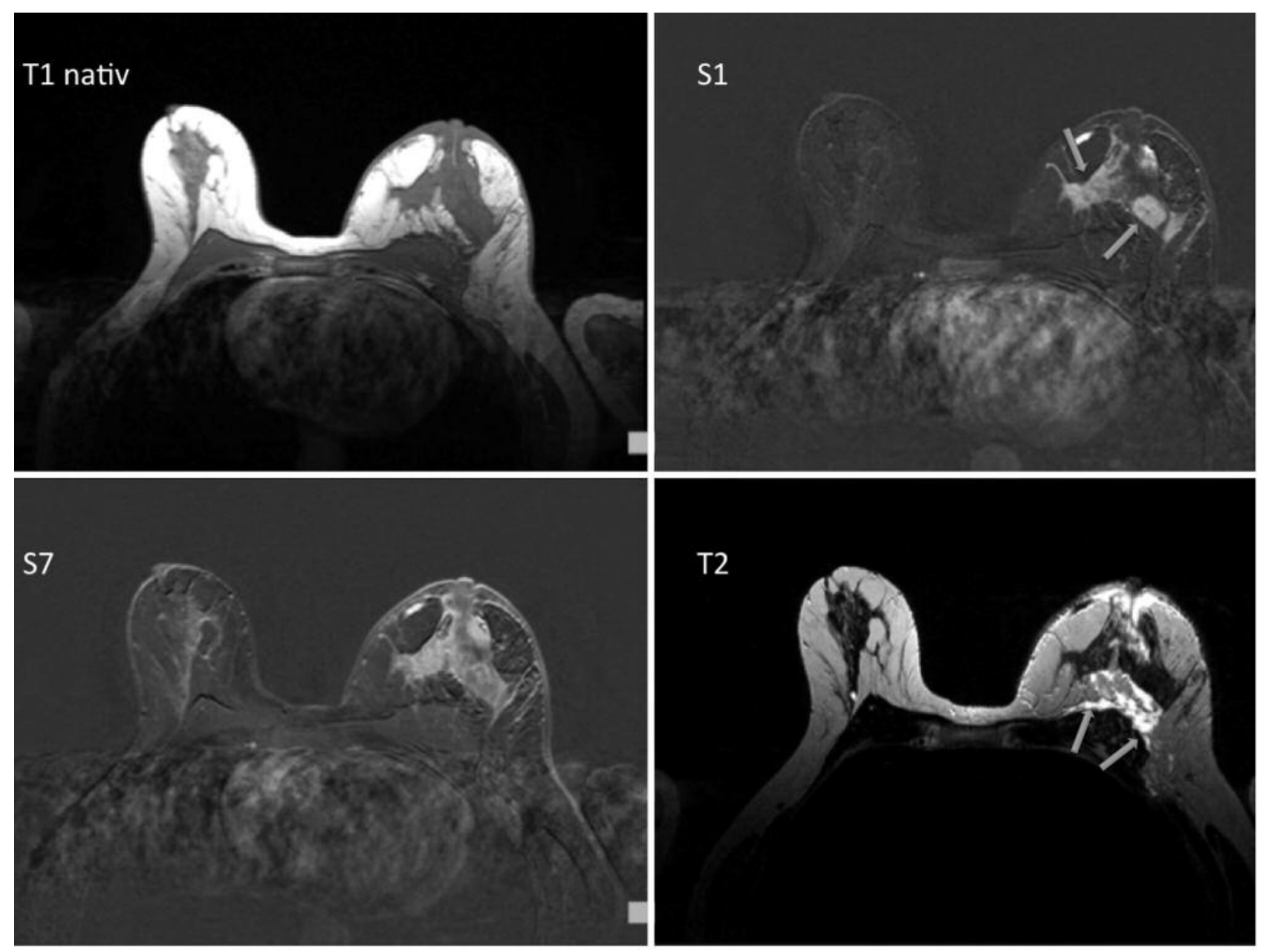

Figure 1. G3 ductal invasive carcinoma with prepectoral edema. Upper left: T1 nativ before the injection of $0.1 \mathrm{mmol} / \mathrm{kg}$ gadolinium. Lower left: Subtraction 1 min post contrast. Upper right: Subtraction 7 min post contrast. Lower right: T2 turbo spin echo (TSE)-weighted image. A 47-yearold patient with G3 ductal invasive carcinoma (blue circle) in the left breast in S1 after the injection of 0.1 mmol/kg gadolinium. The multifocal cancer reveals type 3 kinetic curves and appears hypointense in T2. Accompanying prepectoral edema (PE) is clearly visible in T2, displayed as hyperintense fluid spatters (blue arrows).

known to induce tumor angiogenesis by emitting vascular endothelial growth factor (VEGF) (18).

TAM could, therefore, potentially be involved in an increased lymphangiogenesis by inducing the emission of VEGF-C and VEGF-D, which, besides in regular angiogenesis (19), are involved in the formation of lymphatic vessels $(15,16)$.

Nodal-positive tumors are known to show a particularly tight net of such lymphatic vessels (16). In the case that the transportation capacity of lymphatic vessels is obstipated or else wise exhausted (e.g. through tumor embolisation), formation of lymphedema may occur (17). This explanation of PE would underline our results: PE could be highly significantly correlated to the presence of an accompanying lymphangiosis carcinomatosa $(p<0.000)$ and the infiltration of axillary lymph nodes $(p=0.020)$.
Prognostic information about the nodal status, as well as lymphangiosis, is known to be clinically relevant $(20,21)$, not only determining patients' prognosis but also treatment. The extraction of sentinel nodes or axillary dissection resemble as the standard of care in national guidelines worldwide (22), yet they resemble to invasive surgical procedures (23-25). As the reliable distinction of positive axillary nodes in MRM, hypothetically making a following sentinel nodal biopsy redundant, remains difficult and disputed (26), there is an ongoing need for an increased PPV in the detection of positive axillary nodes. PE, of course, cannot serve as a sole predictor for nodal positivity, yet could serve as an additional diagnostic sign (3) to help form a more accurate and differential diagnosis.

The degree of tumor differentiation is another important prognostic factor $(27,28)$. Various studies have emphasized a 

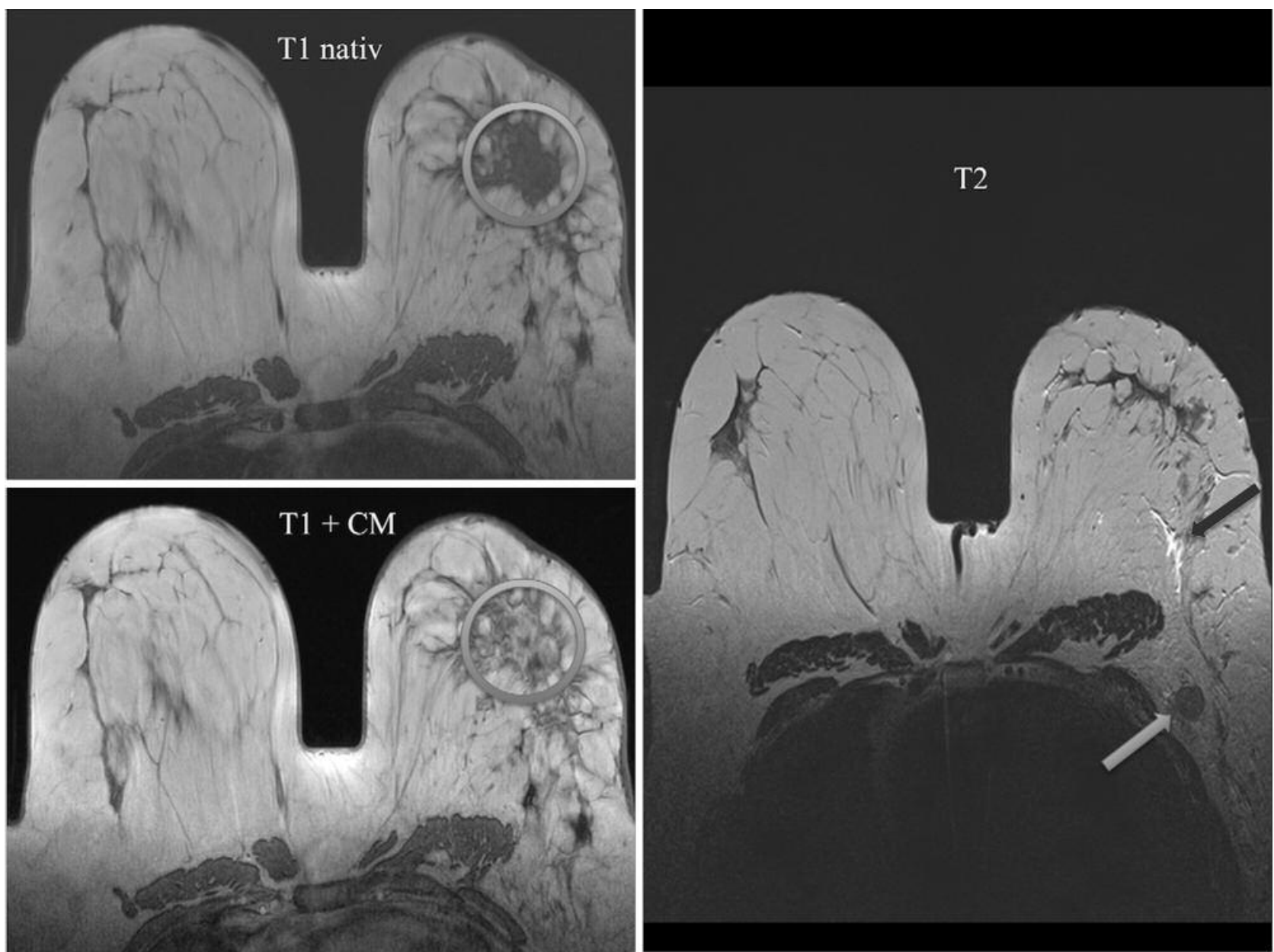

Figure 2. Lobular carcinoma with lymph node metastasis and prepectoral edema. Upper left: T1 before the injection of $0.1 \mathrm{mmol} / \mathrm{kg}$ gadolinium. Lower left: T1, $3 \mathrm{~min}$ after the injection of $0.1 \mathrm{mmol} / \mathrm{kg}$ gGadolinium. Right: T2 turbo spin echo (TSE)-weighted image. Case of a 34-year-old patient with multicentric lobular cancer (blue circle) in the outer aspects of the left breast. The T2w image shows prepectoral edema (PE) (orange arrow) along with a lymph node metastasis (blue arrow) in the left axillary region.

correlation between tumor angiogenesis and the degree of differentiation of breast tumors $(19,29)$. Tumor vessels are characterized by pathologic endothelia, allowing the extension of the extracellular space and, thus, the formation of edema $(30,31)$. Malignant tumors are also known to produce and emit paracrine factors, increasing the permeability of normal, as well as tumor-associated vessels (32). Baltzer et al. (33) emphasized that mal-differentiated carcinomas are significantly more likely to develop accompanying edema. This is in line with the results of our study: The prevalence of PE correlated significantly with mal-differentiated tumors (G3) with decreased patient prognosis.

Another factor, allowing for prognostic conclusions in breast cancer patients is biochemical information. Tumor tissue is regularly examined for the expression of protooncogenes (estrogen, progesterone and HER-2/NEU) as clinical standard, since the receptor status heavily affects the planning of therapy $(34,35)$, e.g. in regards to anti-hormonal therapy planning.

Estrogen is known to regulate tumor angiogenesis, yet a high expression of estrogen receptors leads to a suppression of VEGF release $(36,37)$. According to Fuckar et al. (38), there is a significant correlation between a high expression of VEGF and an estrogen receptor-negative status in breast cancer patients, while ER-negative tumors have a generally worse prognosis. This is different in tumors with a high expression of HER-2 resulting in an additional activation of tumor angiogenesis (38-42) and in a worse prognosis in patients with breast cancer (42).

Since negative ER status or high expression of HER-2 leads to an increased expression of VEGF, it should seem imaginable that such cancers would be accompanied by PE 
more often. This is to some extent in line with the results of our study: $33.3 \%$ of ER-negative cancer patients compared to $23.1 \%$ ER-positive cancer patients displayed PE. In conclusion, it can be assumed that a positive receptor status, as well as the expression of the proto-oncogene HER-2, play a role in the formation of PE. However, the difference between invasive cancers, lacking estrogen/progesterone/ HER-2 receptors and those expressing them, in correlation to accompanying PE, could not be confirmed significantly. The reason remains matter of future research.

Our results are in line with Uematsu et al. (43), also proposing $\mathrm{PE}$ as a sign for malignant tumors and a prognostic factor for an infiltration of the axillary lymph nodes, yet evaluated at $3 \mathrm{~T}$. Other centers need to verify their results with their specific techniques. In that case, T2weighted images should be included to standards of guidelines in MRM more firmly.

In conclusion, it can be summarized that $\mathrm{T} 2$-weighted images in MRM are important for the differential diagnosis of benign and malignant lesions. They do not only contain significant diagnostic "focal" information for the characterization of lesions (18) but, according to our results, also reveal PE to be an additional and helpful diagnostic sign towards invasive advanced stage tumors with worse patient prognosis, requiring more intense treatment.

Our study suffers of some limitations as well, since it was designed as a single-center study. The results of this work were acquired with the specific technique we use in our University Hospital. Our data should be confirmed in a multi-center setting, also investigating different techniques.

A sensitivity of $19.3 \%$ emphasizes the fact that PE is a diagnostic sign that is rather rarely seen. A specificity of $97.3 \%$, however, proves it to be highly valuable in case of its presence, at least for invasive lesions.

Valuable diagnostic signs like PE or e.g., the ductal obstruction sign (44), underline the fact that only few of them are seen in all lesions, which is why they have to be respected in the broad spectrum of all diagnostic signs.

Furthermore, there were no G1 cancer-type lesions in our lesion collective. G1 lesions, in this study, might have confirmed the trend between G2 and G3 lesion in their correlation to PE.

\section{References}

1 Burnside ES, Sickles EA, Bassett LW, Rubin DL, Lee CH, Ikeda DM, Mendelson EB, Wilcox PA, Butler PF and D'Orsi CJ: The ACR BI-RADS ${ }^{\circledR}$ Experience: Learning From History. J Am Coll Radiol JACR 6: 851-860, 2009.

2 Harms SE, Flamig DP, Evans WP, Harries SA and Brown S: MR imaging of the breast: Current status and future potential. Am J Roentgenol 163: 1039-1047, 1994.

3 Kaiser WA: Signs in MR-Mammography. 1st ed. 2008. Corr. 2nd printing. Springer, 2009.
4 Kaiser CG, Reich C, Dietzel M, Baltzer P a. T, Krammer J, Wasser K, Schoenberg SO and Kaiser WA: DCE-MRI of the breast in a stand-alone setting outside a complementary strategy - Results of the TK-study. Eur Radiol 25: 1793-1800, 2015.

5 Dietzel M, Baltzer PAT, Vag T, Gajda M, Camara O and Kaiser WA: The hook sign for differential diagnosis of malignant from benign lesions in magnetic resonance mammography: experience in a study of 1084 histologically verified cases. Acta Radiol Stockh Swed 1987 51: 137-143, 2010.

6 Dietzel M, Baltzer PAT, Vag T, Herzog A, Gajda M, Camara O and Kaiser WA: The necrosis sign in magnetic resonancemammography: diagnostic accuracy in 1,084 histologically verified breast lesions. Breast J 16: 603-608, 2010.

7 Dietzel M, Baltzer PAT, Vag T, Herzog A, Gajda M, Camara O and Kaiser WA: The adjacent vessel sign on breast MRI: new data and a subgroup analysis for 1,084 histologically verified cases. Korean J Radiol Off J Korean Radiol Soc 11: 178-186, 2010.

8 Dietzel M, Baltzer PA, Vag T, Gröschel T, Richter C, Burmeister $\mathrm{H}$ and Kaiser WA: Magnetic resonance mammography in small vs. advanced breast lesions - systematic comparison reveals significant impact of lesion size on diagnostic accuracy in 936 histologically verified breast lesions. RöFo Fortschritte Auf Dem Geb Röntgenstrahlen Nukl 183: 126-135, 2011.

9 Dietzel M, Baltzer PAT, Vag T, Gröschel T, Gajda M, Camara O and Kaiser WA: Application of breast MRI for prediction of lymph node metastases - Systematic approach using 17 individual descriptors and a dedicated decision tree. Acta Radiol Stockh Swed 1987 51: 885-894, 2010.

10 Dietzel M, Baltzer PA, Vag T, Zoubi R, Gröschel T, Burmeister H, Gajda M, Runnebaum IB and Kaiser WA: Potential of MR mammography to predict tumor grading of invasive breast cancer. RöFo Fortschritte Auf Dem Geb Röntgenstrahlen Nukl 183: 826-833, 2011.

11 Dietzel M, Baltzer PAT, Dietzel A, Vag T, Gröschel T, Gajda M, Camara $\mathrm{O}$ and Kaiser WA: Application of artificial neural networks for the prediction of lymph node metastases to the ipsilateral axilla - initial experience in 194 patients using magnetic resonance mammography. Acta Radiol Stockh Swed 1987 51: 851-858, 2010.

12 Kaiser CG, Herold M, Baltzer PAT, Dietzel M, Krammer J, Gajda M, Camara O, Schoenberg SO, Kaiser WA and Wasser K: Is "prepectoral edema" a morphologic sign for malignant breast tumors? Acad Radiol 22: 684-689, 2015.

13 Dietzel M, Zoubi R, Vag T, Gajda M, Runnebaum IB, Kaiser WA and Baltzer PA: Association between survival in patients with primary invasive breast cancer and computer aided MRI. J Magn Reson Imaging JMRI 37: 146-155, 2013.

14 Baltzer PA, Zoubi R, Burmeister HP, Gajda M, Camara O, Kaiser WA and Dietzel M: Computer Assisted Analysis of MR-Mammography Reveals Association Between Contrast Enhancement and Occurrence of Distant Metastasis. Technol Cancer Res Treat, 2012.

15 Jussila L and Alitalo K: Vascular growth factors and lymphangiogenesis. Physiol Rev 82: 673-700, 2002.

16 Schoppmann SF, Birner P, Stöckl J, Kalt R, Ullrich R, Caucig C, Kriehuber E, Nagy K, Alitalo K and Kerjaschki D: Tumorassociated macrophages express lymphatic endothelial growth factors and are related to peritumoral lymphangiogenesis. Am J Pathol 161: 947-956, 2002. 
17 Karkkainen MJ, Jussila L, Ferrell RE, Finegold DN and Alitalo $\mathrm{K}$ : Molecular regulation of lymphangiogenesis and targets for tissue oedema. Trends Mol Med 7: 18-22, 2001.

18 Kuhl CK, Klaschik S, Mielcarek P, Gieseke J, Wardelmann E and Schild HH: Do T2-weighted pulse sequences help with the differential diagnosis of enhancing lesions in dynamic breast MRI? J Magn Reson Imaging JMRI 9: 187-196, 1999.

19 Folkman J, Watson K, Ingber D and Hanahan D: Induction of angiogenesis during the transition from hyperplasia to neoplasia. Nature 339: 58-61, 1989.

20 Fisher B, Bauer M, Wickerham DL, Redmond CK, Fisher ER, Cruz AB, Foster R, Gardner B, Lerner H and Margolese R: Relation of number of positive axillary nodes to the prognosis of patients with primary breast cancer. An NSABP update. Cancer 52: 1551-1557, 1983.

21 Wilking N, Rutqvist LE, Carstensen J, Mattsson A and Skoog L: Prognostic significance of axillary nodal status in primary breast cancer in relation to the number of resected nodes. Stockholm Breast Cancer Study Group. Acta Oncol Stockh Swed 31: 29-35, 1992.

22 AGO-Online -Mamma. Available from: http://www.agoonline.de/de/infothek-fuer-aerzte/leitlinienempfehlungen/ mamma/ [last accessed August 31, 2016].

23 Kissin MW, Querci della Rovere G, Easton D and Westbury G: Risk of lymphoedema following the treatment of breast cancer. Br J Surg 73: 580-584, 1986.

24 Yi M, Giordano SH, Meric-Bernstam F, Mittendorf EA, Kuerer HM, Hwang RF, Bedrosian I, Rourke L and Hunt KK: Trends in and outcomes from sentinel lymph node biopsy (SLNB) alone $v s$. SLNB with axillary lymph node dissection for node-positive breast cancer patients: experience from the SEER database. Ann Surg Oncol 17(Suppl 3): 343-351, 2010.

25 Veronesi U, Paganelli G, Viale G, Luini A, Zurrida S, Galimberti V, Intra M, Veronesi P, Robertson C, Maisonneuve P, Renne G, De Cicco C, De Lucia F and Gennari R: A randomized comparison of sentinel-node biopsy with routine axillary dissection in breast cancer. N Engl J Med 349: 546-553, 2003.

26 Krammer J, Wasser K, Schnitzer A, Henzler T, Schoenberg SO and Kaiser CG: Axillary lymph node characterization in breast cancer patients using magnetic resonance mammography: a prospective comparative study with FDG PET-CT and healthy women. Eur J Radiol 82: 2194-2198, 2013.

27 Roberti NE: The role of histologic grading in the prognosis of patients with carcinoma of the breast: Is this a neglected opportunity? Cancer 80: 1708-1716, 1997.

28 Cross SS: Grading and scoring in histopathology. Histopathology 33: 99-106, 1998

29 Helbich TH: Contrast-enhanced magnetic resonance imaging of the breast. Eur J Radiol 34: 208-219, 2000.

30 Dvorak HF, Dickersin GR, Dvorak AM, Manseau EJ and Pyne K: Human breast carcinoma: Fibrin deposits and desmoplasia. Inflammatory cell type and distribution. Microvasculature and infarction. J Natl Cancer Inst 67: 335-345, 1981.

31 Buadu LD, Murakami J, Murayama S, Hashiguchi N, Sakai S, Masuda K, Toyoshima S, Kuroki S and Ohno S: Breast lesions: Correlation of contrast medium enhancement patterns on MR images with histopathologic findings and tumor angiogenesis. Radiology 200: 639-649, 1996.
32 Senger DR, Connolly DT, Van de Water L, Feder J and Dvorak HF: Purification and NH2-terminal amino acid sequence of guinea pig tumor-secreted vascular permeability factor. Cancer Res 50: 1774-1778, 1990.

33 Baltzer PAT, Yang F, Dietzel M, Herzog A, Simon A, Vag T, Gajda M, Camara $\mathrm{O}$ and Kaiser WA: Sensitivity and specificity of unilateral edema on T2w-TSE sequences in MRMammography considering 974 histologically verified lesions. Breast J 16: 233-239, 2010.

34 Ravdin PM, De Laurentiis M, Vendely T and Clark GM: Prediction of axillary lymph node status in breast cancer patients by use of prognostic indicators. J Natl Cancer Inst 86: 1771$1775,1994$.

35 Donegan WL: Tumor-related prognostic factors for breast cancer. CA Cancer J Clin 47: 28-51, 1997.

36 Ali SH, O’Donnell AL, Balu D, Pohl MB, Seyler MJ, Mohamed $\mathrm{S}$, Mousa $\mathrm{S}$ and Dandona P: Estrogen receptor-alpha in the inhibition of cancer growth and angiogenesis. Cancer Res 60: 7094-7098, 2000.

37 Bogin L and Degani H: Hormonal regulation of VEGF in orthotopic MCF7 human breast cancer. Cancer Res 62: 19481951, 2002.

38 Fuckar D, Dekanić A, Stifter S, Mustać E, Krstulja M, Dobrila $\mathrm{F}$ and Jonjić N: VEGF expression is associated with negative estrogen receptor status in patients with breast cancer. Int J Surg Pathol 14: 49-55, 2006.

39 Bagheri-Yarmand R, Vadlamudi RK, Wang RA, Mendelsohn J and Kumar R: Vascular endothelial growth factor up-regulation via p21-activated kinase-1 signaling regulates heregulin-beta1mediated angiogenesis. J Biol Chem 275: 39451-39457, 2000.

40 Yen L, You XL, Al Moustafa AE, Batist G, Hynes NE, Mader S, Meloche $S$ and Alaoui-Jamali MA: Heregulin selectively upregulates vascular endothelial growth factor secretion in cancer cells and stimulates angiogenesis. Oncogene 19: 34603469, 2000.

41 Kumar $\mathrm{R}$ and Yarmand-Bagheri R: The role of HER2 in angiogenesis. Semin Oncol 28: 27-32, 2001.

42 Konecny GE, Meng YG, Untch M, Wang H-J, Bauerfeind I, Epstein M, Stieber P, Vernes J-M, Gutierrez J, Hong K, Beryt M, Hepp H, Slamon DJ and Pegram MD: Association between HER-2/neu and vascular endothelial growth factor expression predicts clinical outcome in primary breast cancer patients. Clin Cancer Res Off J Am Assoc Cancer Res 10: 1706-1716, 2004.

43 Uematsu T, Kasami $M$ and Watanabe $J$ : Is evaluation of the presence of prepectoral edema on T2-weighted with fatsuppression $3 \mathrm{~T}$ breast MRI a simple and readily available noninvasive technique for estimation of prognosis in patients with breast cancer? Breast Cancer Tokyo 21: 684-692, 2014.

44 Baltzer PAT, Kaiser CGN, Dietzel M, Vag T, Herzog AB, Gajda M, Camara O and Kaiser WA: Value of ductal obstruction sign in the differentiation of benign and malignant breast lesions at MR imaging. Eur J Radiol 75: e18-21, 2010.

Received February 21, 2017

Revised March 10, 2017

Accepted March 13, 2017 